\title{
Changes in plasma amino acid profiles, growth performance and intestinal antioxidant capacity of piglets following increased consumption of methionine as its hydroxy analogue
}

\author{
Hao $\mathrm{Li}^{1} \dagger$, Haifeng Wan ${ }^{1} \dagger$, Yves Mercier ${ }^{2}$, Xiaoling Zhang ${ }^{1}$, Caimei Wu ${ }^{1}$, Xiuqun Wu ${ }^{1}$, Li Tang ${ }^{1}$, \\ Lianqiang $\mathrm{Che}^{1}$, Yan $\mathrm{Lin}^{1}$, Shengyu $\mathrm{Xu}^{1}$, Gang Tian ${ }^{1}$, De $\mathrm{Wu}^{1}$ and Zhengfeng Fang ${ }^{1 *}$ \\ ${ }^{1}$ Key Laboratory for Animal Disease Resistance Nutrition of the Ministry of Education of China, \\ Animal Nutrition Institute, Sichuan Agricultural University, Ya'an 625014, People's Republic of China \\ ${ }^{2}$ Adisseo France S.A.S., CERN, Commentry, France \\ (Submitted 22 July 2013 - Final revision received 22 January 2014 - Accepted 1 February 2014 - First published online 1 August 2014)
}

\section{Abstract}

The aim of the present study was to determine whether early weaning-induced growth retardation could be attenuated by increased consumption of methionine as DL-methionine (DLM) or DL-2-hydroxy-4-methylthiobutyrate (HMTBA) in both lactating sows and weaned piglets. Therefore, diets containing DLM and HMTBA at $25 \%$ of the total sulphur-containing amino acids (AA) present in the control (CON) diet were fed to lactating sows and weaned piglets and their responses were evaluated. Compared with the CON dietfed sows, the HMTBA diet-fed sows exhibited a tendency $(P<0 \cdot 10)$ towards higher plasma taurine concentrations and the DLM dietfed sows had higher $(P<0.05)$ plasma taurine concentrations, but lower $(P<0.05)$ isoleucine concentrations. Suckling piglets in the HMTBA treatment group had higher $(P<0.05)$ intestinal reduced glutathione (GSH) content, lower $(P<0.05)$ oxidised glutathione (GSSG):GSH ratio, and higher $(P<0.05)$ plasma cysteine and glutathione peroxidase $(\mathrm{GPx})$ activity than those in the CON and DLM treatment groups. The feed intake $(P<0.05)$ and body weight of piglets averaged across post-weaning (PW) days were higher $(P<0.05)$ in the HMTBA treatment group than in the DLM treatment group and were higher $(P<0 \cdot 05)$ and tended $(P<0 \cdot 10)$ to be higher, respectively, in the HMTBA treatment group than in the CON treatment group. Increased $(P<0.05)$ GSSG content and GSSG:GSH ratio and down-regulated $(P<0.05)$ expression of nutrient transport genes were observed in the jejunum of piglets on PW day 7 than on PW day 0 . On PW day 14 , the HMTBA diet-fed piglets had higher $(P<0.05)$ intestinal GSH content than the CON diet-fed piglets and higher $(P<0 \cdot 05)$ plasma GPx activity, villus height and goblet cell numbers than the CON diet- and DLM diet-fed piglets. In conclusion, early weaning-induced growth retardation appears to be attenuated through changes in plasma AA profiles and elevation of growth performance and intestinal antioxidant capacity in piglets following increased consumption of methionine as HMTBA.

\section{Key words: Early weaning stress: Intestine: Methionine hydroxy analogues: Antioxidant capacity}

Over the last few years, pigs in the swine industry have largely been weaned at $17 \cdot 2 \mathrm{~d}$ of age, with the average age being $19 \cdot 3 \mathrm{~d}^{(1)}$. Weaning-induced intestinal dysfunction and growth retardation $^{(2,3)}$ have become the major constraints on the practice of improving sow productivity through early weaning. It has been found that gastrointestinal dysfunction induced by early weaning could be attenuated by delayed weaning in pigs $^{(4)}$, which indicates the significance of promoting timely growth of neonatal intestine. Given that milk is the main source of nutrition in sucking piglets, maternal nutrition may affect their overall growth and intestinal development via the regulation of milk quantity and quality. Guan et al. ${ }^{(5)}$ reported that the dietary ratios of true digestible essential amino acids (AA) including methionine:lysine required for milk synthesis in lactating sows should be higher than the values recommended by the National Research Council $(\mathrm{NRC})^{(6)}$. Further studies ${ }^{(7)}$ have shown that compared with those recommended by the $\mathrm{NRC}^{(6)}$, the inclusion levels of methionine and methionine + cysteine should be increased by 15 and $22 \%$, respectively, in an ideal AA profile for

\footnotetext{
Abbreviations: AA, amino acids; CON, control diet; DLM, DL-methionine; GPx, glutathione peroxidase; GSH, reduced glutathione; GSSG, Oxidised glutathione; HMTBA, DL-2-hydroxy-4-methylthiobutyrate; NRC, National Research Council; POGRG, percentage of oxidised glutathione to reduced glutathione; PVHCD, percentage of villus height to crypt depth; PW, post-weaning; SAA, sulphur-containing amino acids.
}

*Corresponding author: Professor Z. Fang, fax +8628 86290920, email fangzhengfeng@hotmail.com

† These authors equally contributed to the study. 
lactating sows. However, no physiological explanation exists for the role of increased methionine consumption in lactating sows and their offspring.

In addition to pre-weaning intestinal development status, the low feed intake is usually considered to be another major factor responsible for intestinal dysfunction and atrophy in weaning piglets ${ }^{(8)}$. Previous work has shown gastrointestinal dysfunction to be physiologically associated with early weaning-induced oxidative stress ${ }^{(3)}$. It has been established that the synthesis of both the major cellular reductant, glutathione $e^{(9)}$, and the major extracellular reductant, cysteine ${ }^{(10)}$, depends on the AA cysteine or its precursor, methionine ${ }^{(11)}$. Moreover, sulphur-containing amino acids (SAA) have been shown to be essential for normal intestinal mucosal growth in neonatal pigs ${ }^{(12)}$, and the suppression of intestinal epithelial growth by SAA deficiency has also been demonstrated in neonatal pigs ${ }^{(13)}$. These functional roles necessitate a constant nutritional intake of SAA. However, the low feed intake in weaning pigs, especially during the first few post-weaning (PW) days, may decrease the supply of nutritional SAA to levels lower than that practically required.

DL-Methionine (DLM) and its hydroxy analogue, DL-2-hydroxy-4-methylthiobutyrate (HMTBA), are routinely used as methionine supplements in livestock industry. Our previous studies ${ }^{(14-17)}$ in pigs have shown the differences in the absorption and metabolism of these two methionine sources. The objective of the present study was to determine whether early weaning-induced growth retardation could be attenuated by increased consumption of methionine as DLM or HMTBA in both lactating sows and weaned piglets. Plasma and milk AA profiles and intestinal morphology, antioxidant capacity and mRNA abundance of genes related to nutrient transport were also evaluated, which may provide a biological explanation for performance responses.

\section{Materials and methods}

\section{Animals and diets}

The study protocol was approved by the Animal Care and Use Committee of Animal Nutrition Institute, Sichuan Agricultural University, and the study was carried out in accordance with the NRC Guide for the Care and Use of Laboratory Animals. A total of eighteen pregnant crossed (Landrace $\times$ Yorkshire) primiparous sows (with similar body weight and backfat thickness) were used in the experiment. On day 110 of gestation, sows were moved into farrowing crates $(2.1 \times 0.7 \mathrm{~m})$ with an area $(2.1 \times 0.6 \mathrm{~m})$ allocated to newborn piglets on each side of the crates in an environmentally regulated farrowing house. Temperature was maintained at $20 \pm 1^{\circ} \mathrm{C}$ in the farrowing house, and heat lamps provided supplemental heat to the pigs. All sows were fed the control (CON) diet until farrowing, after which six sows were continued to be fed the CON diet and the other sows were fed either the DLM or the HMTBA diet (six sows per dietary treatment). The CON diet for lactating sows was formulated based on the $\mathrm{NRC}^{(6)}$ lactating sow nutritional requirement values (Table 1). The DLM and HMTBA diets were prepared by adding DLM and HMTBA to the CON diet, respectively, at $25 \%$ of the total SAA present in the CON diet, such that the ratio of methionine + cysteine:lysine approached that recommended by Dourmad et $a l .{ }^{(7)}$. Within $12 \mathrm{~h}$ of farrowing, all litters were standardised to have ten piglets per sow. On postnatal day 14, all litters were standardised to have nine piglets per sow, and piglets were given free access to the diets that they continued to receive after weaning. Piglets from the CON, DLM and HMTBA groups of sows were fed the weaned diets CON, DLM and HMTBA, respectively. The CON diet for piglets was formulated based on the $\mathrm{NRC}^{(6)}$ piglet nutritional requirement values (Table 2). The DLM and HMTBA diets were

Table 1. Ingredients and composition of the control (CON) diet of sows*

\begin{tabular}{lclr}
\hline Ingredients & Content $(\mathrm{kg})$ & Composition & $\%$ \\
\hline Maize & 582 & CP & $16 \cdot 10$ \\
Wheat bran & 60 & Lysine & 0.97 \\
Soyabean meal (CP 43\%) & 240 & Methionine & 0.25 \\
Fructose-glucose syrup & 20 & Methionine+cystine & 0.53 \\
Glucose & 25 & Threonine & 0.63 \\
Soyabean oil & 35 & Tryptophan & $0 \cdot 19$ \\
Lysine-HCl & 1.45 & Valine & 0.83 \\
Threonine & 0.08 & Digestible Lysine & 0.85 \\
Valine (99\%) & 0.92 & Digestible methionine & 0.23 \\
Dicalcium phosphate & $14 \cdot 1$ & Digestible methionine+cystine & 0.46 \\
Limestone & 10.5 & Ca & 0.80 \\
NaCl & 4 & Total P & 0.64 \\
Premix $\ddagger$ & 5 & Available P & 0.38 \\
Choline chloride $(50 \%)$ & 2 & & \\
Total & 1000 & &
\end{tabular}

$\mathrm{CP}$, crude protein.

* The DL-methionine (DLM) and DL-2-hydroxy-4-methylthiobutyrate (HMTBA) diets were prepared by adding $1.34 \mathrm{~kg}$ of DLM $(99 \%)$ and $1.51 \mathrm{~kg}$ of HMTBA $(88 \%)$ to the CON diet at the expense of maize to supply $25 \%$ of the total sulphur-containing amino acids. Each diet (per kg) contained $14200 \mathrm{~kJ}$ digestible energy.

†Provided the following per $\mathrm{kg}$ of diet: retinol, $3600 \mu \mathrm{g}$; vitamin $\mathrm{D}_{3}, 70 \mu \mathrm{g}$; vitamin $\mathrm{E}, 100 \mathrm{mg}$; menadione, $3.5 \mathrm{mg}$; thiamin, $3.5 \mathrm{mg}$; riboflavin, $8.5 \mathrm{mg}$; niacin, $35 \mathrm{mg}$; D-panthothenic acid, $21 \mathrm{mg}$; vitamin $\mathrm{B}_{6}, 3.5 \mathrm{mg}$; vitamin $\mathrm{B}_{12}, 35 \mu \mathrm{g}$; D-biotin, $420 \mu \mathrm{g}$; folic acid, $2.5 \mathrm{mg}$.

‡Provided the following per kg of diet: $\mathrm{Cu}, 10 \mathrm{mg} ; \mathrm{Fe}, 120 \mathrm{mg} ; \mathrm{Mn}, 30 \mathrm{mg} ; \mathrm{Zn}, 80 \mathrm{mg} ; \mathrm{I}, 0.21 \mathrm{mg}$; Se, $0.23 \mathrm{mg}$; antioxidant, $100 \mathrm{mg}$; anti-mould additive, $500 \mathrm{mg}$. 
Table 2. Ingredients and composition of the control (CON) diet of piglets*

\begin{tabular}{|c|c|c|c|}
\hline Ingredients & Content (kg) & Composition & $\%$ \\
\hline Extruded maize & 502 & $\mathrm{CP}$ & $19 \cdot 70$ \\
\hline Extruded soyabean & 120 & Lysine & 1.35 \\
\hline Dried whey (CP $3 \%)$ & 120 & Methionine & 0.39 \\
\hline Soyabean meal (CP $43 \%)$ & 121 & Methionine + cystine & 0.76 \\
\hline Fishmeal (CP 65\%) & 40 & Threonine & 0.86 \\
\hline Fructose-glucose syrup & 10 & Tryptophan & 0.26 \\
\hline Glucose & 20 & Digestible lysine & 1.22 \\
\hline Porcine plasma & 40 & Digestible methionine & 0.36 \\
\hline Lysine- $\mathrm{HCl}$ & 1.50 & Digestible methionine+cystine & 0.68 \\
\hline Methionine & 0.55 & Digestible threonine & 0.75 \\
\hline Threonine & 0.24 & Digestible tryptophan & 0.23 \\
\hline Dicalcium phosphate & 7.62 & $\mathrm{Ca}$ & 0.80 \\
\hline Limestone & $7 \cdot 68$ & Total P & 0.65 \\
\hline $\mathrm{NaCl}$ & 3 & Available P & 0.45 \\
\hline $\mathrm{ZnO}$ & 2.5 & & \\
\hline Premix†‡ & 3 & & \\
\hline Choline chloride (50\%) & 1 & & \\
\hline Total & 1000 & & \\
\hline
\end{tabular}

$\mathrm{CP}$, crude protein.

* The DL-methionine (DLM) and DL-2-hydroxy-4-methylthiobutyrate (HMTBA) diets were prepared by adding $1.92 \mathrm{~kg}$ of DLM (99\%) and $2.16 \mathrm{~kg}$ of HMTBA ( $88 \%)$, respectively, to the CON diet at the expense of maize to supply $25 \%$ of the total sulphur-containing amino acids. Each diet (per $\mathrm{kg}$ ) contained $14200 \mathrm{~kJ}$ digestible energy.

†Provided the following per $\mathrm{kg}$ of diet: retinol, $3000 \mu \mathrm{g}$; vitamin $\mathrm{D}_{3}, 60 \mu \mathrm{g}$; vitamin $\mathrm{E}, 60 \mathrm{mg}$; menadione, $3 \mathrm{mg}$; thiamin, $3 \mathrm{mg}$; riboflavin, $7.5 \mathrm{mg}$; niacin, $30 \mathrm{mg}$; D-panthothenic acid, $18 \mathrm{mg}$; vitamin $\mathrm{B}_{6}, 3 \mathrm{mg}$; vitamin $\mathrm{B}_{12}, 30 \mu \mathrm{g}$; D-biotin, $360 \mu \mathrm{g}$; folic acid, $2.1 \mathrm{mg}$.

¥Provided the following per kg of diet: $\mathrm{Cu}, 200 \mathrm{mg}$; Fe, $150 \mathrm{mg}$; Mn, $20 \mathrm{mg} ; \mathrm{Zn}, 150 \mathrm{mg}$; I, 0.3 mg; Se, $0.3 \mathrm{mg}$; antioxidant, $100 \mathrm{mg}$; anti-mould additive, $800 \mathrm{mg}$.

prepared by adding DLM and HMTBA to the CON diet, respectively, at $25 \%$ of the total SAA present in the CON diet. Piglets from three of the six sows in each group were weaned on postnatal days 21 and 28 , respectively.

\section{Collection of blood, milk and tissue samples}

At $30 \mathrm{~min}$ before the morning meal on postpartum day 21, following an overnight period of feed withdrawal, blood samples $(10 \mathrm{ml})$ were withdrawn from the superior vena cava of each sow into heparinised tubes and immediately centrifuged for $10 \mathrm{~min}$ at $2550 \mathrm{~g}$ and $4^{\circ} \mathrm{C}$. The supernatants were divided into four subsamples and stored at $-20^{\circ} \mathrm{C}$ until analysis. Milk samples $(20 \mathrm{ml})$ were also collected from each sow on day 21 before the morning meal as described previously ${ }^{(18)}$. Briefly, piglets were separated from their dams for 90 min initially, and then 10 international units (IU) of oxytocin (a nonapeptide, 1 IU of oxytocin is the equivalent of about $2 \mu \mathrm{g}$ of pure peptide) were injected into the ear vein of each sow, and the functional pectoral and inguinal glands were milked manually to collect milk samples, which were stored at $-20^{\circ} \mathrm{C}$ until analysis.

At 30 min before the morning meal on postnatal days 21, 28 and 35, following an overnight period of feed withdrawal, blood samples were collected from the jugular vein of one pig in each litter as described previously ${ }^{(19)}$. Immediately after the collection of blood samples, pigs were anaesthetised and bled by exsanguination as described previously ${ }^{(17)}$. A total of fifty-four piglets were slaughtered according to the treatment groups (Table 3). Immediately after slaughter, the abdomen was opened, and the entire intestine was rapidly removed, thoroughly fluxed with sterile saline to remove luminal digesta and then dissected free of mesenteric attachments and placed on a smooth, cold-surface tray. A $2 \mathrm{~cm}$

Table 3. Feeding treatments for piglets before slaughter*

\begin{tabular}{lcc}
\hline \multicolumn{3}{c}{ Slaughter time } \\
\hline Postnatal day $21(n 6)$ & Postnatal day $28(n 3)$ & Postnatal day $35(n$ 3) \\
\hline CON-21 & CON-28 & CON-28+CON-7PW \\
& CON-21+CON-7PW & CON-21+CON-14PW \\
DLM-21 & DLM-28 & DLM-28+DLM-7PW \\
& DLM-21+DLM-7PW & DLM-21+DLM-14PW \\
HMTBA-21 & HMTBA-28 & HMTBA-28+HMTBA-7PW \\
& HMTBA-21+HMTBA-7PW & HMTBA-21+HMTBA-14PW
\end{tabular}

CON, control; PW, post-weaning; DLM, DL-methionine; HMTBA, DL-2-hydroxy-4-methylthiobutyrate.

* In CON-21 treatment, piglets were reared for $21 \mathrm{~d}$ by sows fed the CON diet; in CON-7PW treatment, piglets were fed the CON diet for seven PW days; and in CON-21+CON-7PW treatment, piglets were reared for $21 \mathrm{~d}$ by the CON diet-fed sows and then weaned to be fed the CON diet for seven PW days. The rest of the treatments can be deduced by analogy. 
Table 4. Primers used in real-time PCR analysis of gene expression in pig jejunum

\begin{tabular}{|c|c|c|c|}
\hline Genes & Accession number & Primers & Length (bp) \\
\hline $18 \mathrm{~S}$ ribosomal RNA & NR_046261.1 & $\begin{array}{l}\text { Forward: 5'-GACTCAACACGGGAAACCTCAC-3' } \\
\text { Reverse: 5'-ATCGCTCCACCAACTAAGAACG-3' }\end{array}$ & 114 \\
\hline Apo A-IV precursor & NM_214388.1 & $\begin{array}{l}\text { Forward: 5'-GTGGCTACTGTGATGTGGGACTAC-3' } \\
\text { Reverse: 5'-CCAAGTTTGTCCTGGAAGAGAGTG-3' }\end{array}$ & 94 \\
\hline FZHUI fatty acid-binding protein intestinal & NM_001031780.1 & $\begin{array}{l}\text { Forward: 5'-TACAGCCTCGCAGACGGAAC-3' } \\
\text { Reverse: 5'-CCTCTTGGCTTCTACTCCTTCATAC-3' }\end{array}$ & 90 \\
\hline $\mathrm{Na}-$ and $\mathrm{Cl}$-dependent creatine transporter I & NM_001177327.1 & $\begin{array}{l}\text { Forward: 5'-TCGACTACTACTCGGCCAGCG-3' } \\
\text { Reverse: 5'-ACCAGCGGGGTGAAGAAAGAC-3' }\end{array}$ & 77 \\
\hline
\end{tabular}

section of tissue samples representing duodenum, jejunum and ileum was collected as described previously ${ }^{(20)}$ and stored at $-80^{\circ} \mathrm{C}$ for subsequent RNA isolation. Samples of intestinal segments were collected for the assessment of intestinal morphology ${ }^{(21)}$. The intestinal segments were opened lengthwise and pinned to a piece of dental wax with the serosal side facing the wax. Subsequently, the samples were fixed in $4 \%$ paraformaldehyde solution with the mucosal side facing downwards to fix the villi vertically ${ }^{(22)}$.

\section{Measurements}

Growth performance determination. The body weight of sows was determined before the morning meal on postpartum days 0,21 and 28. The backfat thickness of sows was measured $65 \mathrm{~mm}$ from the left side of the dorsal midline at the last rib level (P2) using ultrasound (Renco Lean-Meater) on postpartum days 0,21 and 28 . The body weight of piglets was determined before the morning meal on postnatal days $0,21,28$ and 35 . The feed intake of each sow and each litter of piglets was recorded daily.

\section{Amino acids analysis}

For free AA analysis, the frozen plasma and milk samples were thawed at $4^{\circ} \mathrm{C}$. The protein precipitation procedure was carried out as described previously ${ }^{(23)}$. Briefly, $1 \mathrm{ml}$ of the sample and $2.5 \mathrm{ml}$ of $7.5 \%(\mathrm{w} / \mathrm{v})$ TCA solution were mixed thoroughly and centrifuged at $12000 \mathrm{~g}$ and $4^{\circ} \mathrm{C}$ for $15 \mathrm{~min}$. Then, the supernatant was collected and analysed for AA by ion-exchange chromatography using an L8800 high-speed AA analyser (Hitachi) as described by Yin et al. ${ }^{(24)}$.

\section{Histological procedure}

Intestinal morphology was examined as described in detail by Berkeveld et al. ${ }^{(25)}$. From each segment, two transverse tissue sections were cut using a stereo microscope. These sections were dehydrated, embedded together in paraffin wax and sectioned at $5 \mu \mathrm{m}$. Later, one section was transferred onto a slide and stained with haematoxylin and eosin. Hence, each slide contained two transverse tissue sections of a gut segment. The height of twelve villi and depth of twelve crypt were determined in each slide using the Nikon Eclipse 80I fluorescence microscope (Nikon) equipped with an epifluorescence image analysis system. Villi and crypts were only measured when there was a complete longitudinal section of a villus and an associated crypt. The average villus height and crypt depth per slide were used as experimental observation values. The number of goblet cells in the intestinal mucosa was determined by periodic acid-Schiff-haematoxylin staining of intestinal sections ${ }^{(26)}$, and it is expressed per $1000 \mu \mathrm{m}$ length of a villus.

\section{Antioxidant capacity analysis}

Frozen jejunal samples were rapidly thawed at $4^{\circ} \mathrm{C}$ and homogenised on ice in twenty volumes (w/v) of ice-cold physiological saline and centrifuged at $4000 \mathrm{~g}$ for $20 \mathrm{~min}$ at $4^{\circ} \mathrm{C}$, and then the supernatants were collected for reduced glutathione (GSH) and oxidised glutathione (GSSG) analysis. GSH and GSSG contents in the samples were determined using a method described previously ${ }^{(27)}$. Briefly, total glutathione content was determined by calculating the rate of reduction of 5,5'-dithiobis-2-nitrobenzoic acid by GSH at $412 \mathrm{~nm}$ and comparing this with a GSH standard curve. GSSG content in the samples was determined using the same method after treating the samples with 4-vinylpyridine for $60 \mathrm{~min}$. GSH content was calculated as follows: total glutathione content $-2 \times$ GSSG content. Protein concentration in jejunal samples was measured using the Bradford method ${ }^{(28)}$. The activity of glutathione peroxidase (GPx) in plasma was determined by quantifying the rate of $\mathrm{H}_{2} \mathrm{O}_{2}$-induced oxidation of $\mathrm{GSH}$ to

Table 5. Backfat thickness, body weight and feed intake of sows on postpartum days 0,21 and 28

(Mean values with their pooled standard errors)

\begin{tabular}{lrrrr}
\hline & CON & DLM & HMTBA & $\begin{array}{c}\text { Pooled } \\
\text { SEM }\end{array}$ \\
\hline Backfat thickness (mm) & & & & \\
$\quad$ Day 0 & 11.06 & 11.17 & 12.83 & 1.65 \\
$\quad$ Day 21 & 11.83 & 10.94 & 13.61 & 2.06 \\
$\quad$ Day 28 & 13.13 & 10.22 & 11.78 & 0.94 \\
Body weight (kg) & & & & \\
$\quad$ Day 0 & 155.68 & 145.27 & 154.80 & 13.10 \\
$\quad$ Day 21 & 157.38 & 145.88 & 154.38 & 11.95 \\
$\quad$ Day 28 & 162.90 & 138.57 & 154.27 & 11.63 \\
Total feed intake (kg) & & & & \\
$\quad$ Days 0-21 & 111.54 & 105.73 & 109.58 & 12.20 \\
$\quad$ Days 22-28 & 40.88 & 44.12 & 39.49 & 7.42 \\
Energy intake (kJ)* & & & & \\
$\quad$ Days 0-21 & 1695.80 & 1701.80 & 1690.22 & 141.62 \\
$\quad$ Days 22-28 & 1817.52 & 2215.94 & 1821.33 & 295.73 \\
\hline
\end{tabular}

CON, control; DLM, DL-methionine; HMTBA, DL-2-hydroxy-4-methylthiobutyrate.

* Calculated based on daily digestible energy intake as a percentage of metabolic body weight. 
Table 6. Comparison of the body weight gain $(\mathrm{kg})$ of piglets weaned at $28 \mathrm{~d}$ of age with that of piglets weaned at $21 \mathrm{~d}$ of age at each of the experimental phases*

(Mean values with their pooled standard errors)

\begin{tabular}{lllccr}
\hline \multicolumn{5}{c}{$\begin{array}{c}\text { Weaning } \\
\text { time }\end{array}$} \\
\cline { 3 - 4 } Phases & Diets & $21 \mathrm{~d}$ & $28 \mathrm{~d}$ & Pooled SEM & \multicolumn{1}{c}{$P$} \\
\hline Days 21-28 & CON & 0.31 & 1.92 & 0.29 & $<0.01$ \\
& DLM & 0.20 & 1.75 & 0.16 & $<0.01$ \\
& HMTBA & 0.41 & 1.71 & 0.23 & $<0.01$ \\
Days 28-35 & CON & 1.27 & 0.32 & 0.24 & 0.01 \\
& DLM & 1.01 & 0.18 & 0.23 & $<0.05$ \\
& HMTBA & 1.53 & 0.63 & 0.42 & $<0.05$ \\
Days 21-35 & CON & 1.59 & 2.24 & 0.31 & 0.13 \\
& DLM & 1.21 & 1.93 & 0.31 & $<0.10$ \\
& HMTBA & 1.93 & 2.34 & 0.54 & 0.33 \\
\hline
\end{tabular}

CON, control; DLM, DL-methionine; HMTBA, DL-2-hydroxy-4-methylthiobutyrate.

* Within each of the phases, there were no differences $(P>0.10)$ among the dietary treatment groups.

GSSG as described previously ${ }^{(29)}$. One unit of GPx was defined as the amount required to reduce the level of GSH by $1 \mu \mathrm{mol} / 1$ in $5 \mathrm{~min}$ per $0 \cdot 1 \mathrm{ml}$ of plasma. The activity of GPx in plasma is expressed as units $/ 10 \mu \mathrm{l}$.

\section{RNA extraction and real-time $P C R$}

Jejunal tissue samples were used to determine the expression of genes related to the intestinal transport of dietary nutrients. The analysed genes included apo A-IV precursor, FZHUI (fatty acid binding protein human intestine) fatty acid-binding protein, and Na- and $\mathrm{Cl}$-dependent creatine transporter I. Total RNA was extracted from the frozen samples using the RNAiso Plus reagent (Takara Bio, Inc.) according to the manufacturer's specifications. The concentration of RNA in the samples was determined using a DU-800 nucleic and protein detector (Beckman) at an optical density (OD) of $260 \mathrm{~nm}$; an $\mathrm{OD}_{260}: \mathrm{OD}_{280}$ ratio ranging between 1.8 and 2.0 was considered acceptable. The integrity of RNA was verified by electrophoresis on a $1 \%$ agarose gel stained with ethidium bromide. Real-time quantitative PCR analysis was carried out using the SYBR Green method and the ABI 7900HT Sequence Detection System. Briefly, first-strand complementary DNA were synthesised from $1 \mu \mathrm{g}$ of total RNA as described previously ${ }^{(15)}$. The thermal cycling parameters were as follows: $95^{\circ} \mathrm{C}$ for $30 \mathrm{~s}$, followed by forty cycles at $95^{\circ} \mathrm{C}$ for $15 \mathrm{~s}$ and $60^{\circ} \mathrm{C}$ for $34 \mathrm{~s}$, followed by $95^{\circ} \mathrm{C}$ for $15 \mathrm{~s}, 60^{\circ} \mathrm{C}$ for $1 \mathrm{~min}$ and $95^{\circ} \mathrm{C}$ for $15 \mathrm{~s}$. To confirm specific product amplification, a melting curve analysis was carried out, and the PCR products were also detected by ethidium bromide staining of the $2 \%$ agarose gels after electrophoresis using Tris-acetate-EDTA buffer. Primers for individual genes were designed using Primer Express 3.0 (Applied Biosystems). Primers used in real-time PCR analysis of gene expression in pig jejunum are given in Table 4. The standard curve of each gene was run in duplicate and three times for obtaining reliable amplification efficiency values as described previously ${ }^{(30)}$. The correlation coefficients $(r)$ of all the standard curves were $>0.99$ and the amplification efficiency values were between 90 and $110 \%$. The relative mRNA abundances of the analysed genes were calculated using the $2^{-\Delta \Delta C_{\mathrm{T}}} \operatorname{method}^{(31)}$, and all the data were normalised to those of the $18 \mathrm{SNA}{ }^{(32)}$ in the same samples.

\section{Statistical analysis}

Data were analysed as described by Littell et al. ${ }^{(33)}$. The MIXED procedures of SAS statistical package (version 8.1; SAS Institute, Inc.) were used to analyse repeated-measures data including body weight, feed intake, intestinal morphology, antioxidant capacity and mRNA abundance data. The generalised linear model procedures of SAS statistical package (version 8.1; SAS Institute, Inc.) were used to analyse data such as AA concentrations, which were measured at a single time point. Means of the dietary treatment groups were compared using the least-significant difference test when the $F$ test in the ANOVA was significant. $P$ values $<0.05$ were considered statistically significant and $P$ values $<0 \cdot 10$ were considered a tendency towards difference.

\section{Results}

\section{Growth performance}

There was no difference in the body weight and backfat thickness of sows on postpartum days 0,21 and 28 $(P>0 \cdot 10)$ among the dietary treatment groups (Table 5). There was no difference in total feed intake and energy
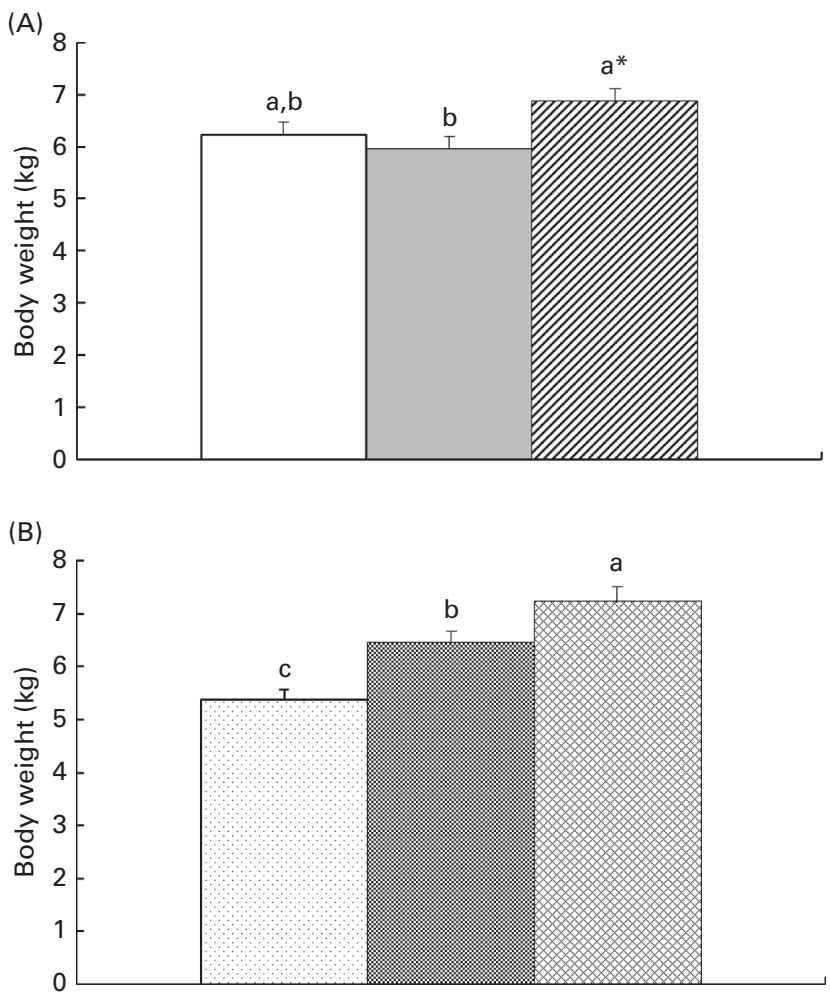

Fig. 1. Effects of (A) dietary treatment ( $\square$, control (CON); $\square$, DL-methionine; 四, DL-2-hydroxy-4-methylthiobutyrate) and (B) age (国, $21 \mathrm{~d}$; 圈, $28 \mathrm{~d}$; 国; $35 \mathrm{~d}$ ) on the body weight of piglets measured over postnatal days. Values are means, with their standard errors represented by vertical bars. ${ }^{a, b, c}$ Mean values with unlike letters were significantly different $(P<0.05)$. ${ }^{*}$ Mean value tended to be different from that of the CON group $(P<0 \cdot 10)$. 

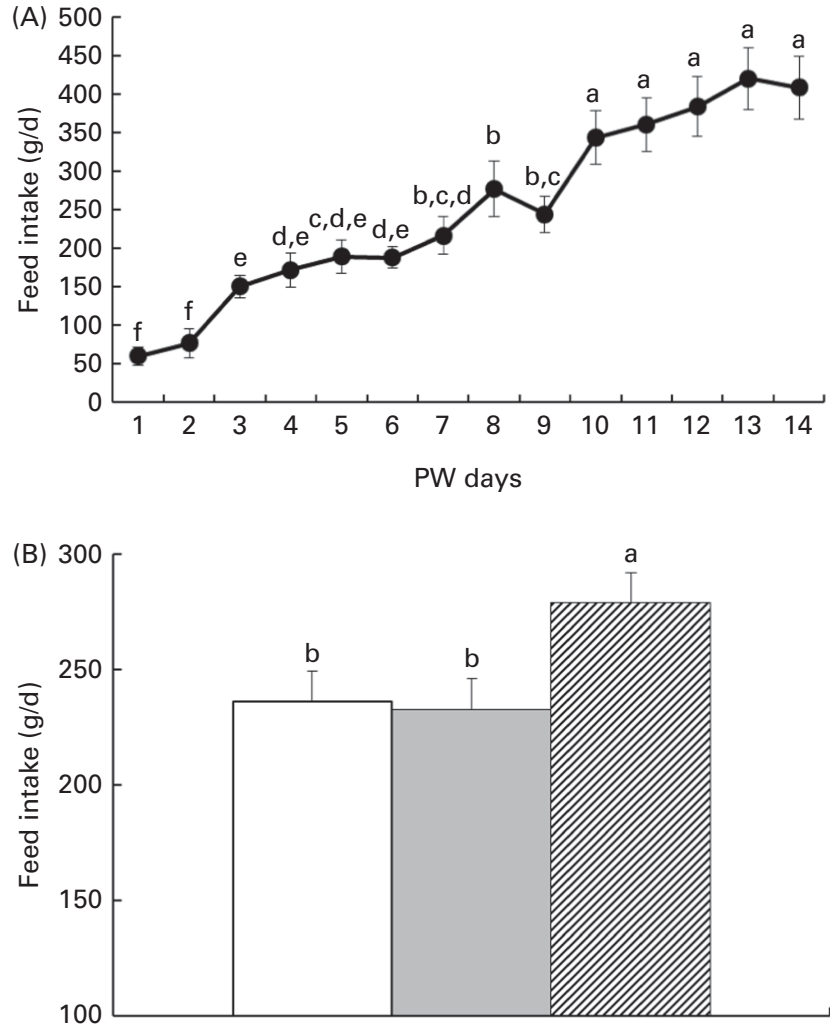

Fig. 2. Effects of (A) post-weaning (PW) day and (B) dietary treatment ( $\square$ control; $\square$, DL-methionine; $\mathbb{}$, DL-2-hydroxy-4-methylthiobutyrate) on the feed intake of piglets weaned at $21 \mathrm{~d}$ of age. Values are means, with their standard errors represented by vertical bars. ${ }^{\mathrm{a}, \mathrm{b}, \mathrm{c}, \mathrm{d}, \mathrm{e}}$ Mean values with unlike letters were significantly different $(P<0.05)$.

intake per metabolic body weight $(P>0 \cdot 10)$ among the dietary treatment groups during each of the experimental phases. Piglets weaned at $21 \mathrm{~d}$ of age had lower $(P<0 \cdot 01)$ day $21-28$ weight gain, but higher $(P<0.05)$ day $28-35$ weight gain than those weaned at $28 \mathrm{~d}$ of age (Table 6). There was no difference in piglet weight gain $(P>0 \cdot 10)$ among the dietary treatment groups during these experimental phases. However, it was found that the body weight of piglets averaged over postnatal days was significantly $(P<0.05)$ higher in the HMTBA treatment group than in the DLM treatment group and tended $(P<0 \cdot 10)$ to be higher in the HMTBA treatment group than in the CON treatment group (Fig. 1(A)). With an increase in age, a significant $(P<0.05)$ increase was observed in the body weight of piglets (Fig. 1(B)). A gradual increase was observed in the feed intake of piglets from PW day 1 to day 14 (Fig. 2(A)). Specifically, feed intake was higher $(P<0.05)$ on PW day 3 than on PW days 1 and 2 , and a further significant $(P<0.05)$ increase was observed on PW days 7 and 10. Overall, feed intake averaged across PW days was higher $(P<0.05)$ in the HMTBA treatment group than in the CON and DLM treatment groups (Fig. 2(B)).

\section{Plasma free amino acid concentrations of sows}

The effects of diets with supplemental DLM or HMTBA on the plasma free AA concentrations of sows on postpartum day 21 are summarised in Table 7. Plasma methionine concentrations showed a tendency $(P<0 \cdot 10)$ to be affected by the dietary treatments. Compared with those in the CON diet-fed sows, plasma taurine concentrations tended $(P<0 \cdot 10)$ to be higher in the HMTBA diet-fed sows, and higher $(P<0.05)$ taurine concentrations but lower $(P<0.05)$ isoleucine concentrations and a tendency $(P<0 \cdot 10)$ towards lower lysine concentrations were observed in the DLM diet-fed sows. The DLM diet- and HMTBA diet-fed sows had higher $(P<0.05)$ plasma free alanine concentrations, but lower $(P<0.05)$ citrulline concentrations than the CON diet-fed sows.

\section{Milk free amino acid concentrations of sows}

The effects of diets with supplemental DLM or HMTBA on the milk free AA concentrations of sows on postpartum day 21 are summarised in Table 8. Milk free leucine and phenylalanine concentrations were higher $(P<0.05)$ in the DLM diet-fed sows than in the CON diet- and HMTBA diet-fed sows. Compared with the CON diet-fed sows, the HMTBA diet-fed sows had higher $(P<0.05)$ milk free taurine concentrations and exhibited a tendency $(P<0 \cdot 10)$ towards higher valine concentrations, whereas the DLM diet-fed sows had higher $(P<0.05)$ valine concentrations and exhibited a tendency $(P<0 \cdot 10)$ towards higher taurine concentrations. Milk free alanine concentrations were higher $(P<0.05)$ and histidine concentrations tended $(P<0 \cdot 10)$ to be higher in the HMTBA diet-fed sows than in the CON dietfed sows. The HMTBA diet-fed sows also had higher $(P<0 \cdot 05)$ milk free histidine concentrations and exhibited a tendency $(P<0 \cdot 10)$ towards higher alanine and ornithine concentrations compared with the DLM diet-fed sows.

\section{Plasma free amino acid concentrations of piglets}

The effects of sow diets with supplemental DLM or HMTBA on the plasma free AA concentrations of suckling piglets on

Table 7. Effects of diets with supplemental DL-methionine (DLM) or DL-2-hydroxy-4-methylthiobutyrate (HMTBA) on the plasma free amino acid concentrations $(\mu \mathrm{mol} / \mathrm{l})$ of sows on postpartum day 21

(Mean values with their pooled standard errors)

\begin{tabular}{lcccc}
\hline Amino acids & CON & DLM & HMTBA & Pooled SEM \\
\hline Met & 45 & 56 & 57 & 7 \\
Lys & $109^{\mathrm{a}, \mathrm{b}}$ & $71^{\mathrm{b} *}$ & $117^{\mathrm{a}}$ & 26 \\
Leu & 202 & 178 & 208 & 29 \\
Ile & $117^{\mathrm{a}}$ & $87^{\mathrm{b}}$ & $122^{\mathrm{a}}$ & 15 \\
Phe & 78 & 80 & 82 & 10 \\
Val & 275 & 259 & 281 & 36 \\
His & 61 & 60 & 68 & 11 \\
Pro & 175 & 224 & 196 & 36 \\
Arg & 85 & 83 & 101 & 18 \\
Ala & $338^{\mathrm{b}}$ & $627^{\mathrm{a}}$ & $532^{\mathrm{a}}$ & 89 \\
Ser & 104 & 116 & 121 & 16 \\
Glu & 91 & 121 & 102 & 22 \\
Tyr & 106 & 107 & 116 & 16 \\
Cit & $72^{\mathrm{a}}$ & $12^{\mathrm{b}}$ & $16^{\mathrm{b}}$ & 15 \\
Orn & 33 & 40 & 38 & 7 \\
Tau & $19^{\mathrm{b}}$ & $34^{\mathrm{a}}$ & $30^{\mathrm{a}, \mathrm{b} *}$ & 6 \\
\hline
\end{tabular}

CON, control.

${ }^{a, b}$ Mean values within a row with unlike superscript letters were significantly different $(P<0.05)$.

${ }^{\star}$ Mean value tended to be different from that of the CON group $(P<0 \cdot 10)$. 
Table 8. Effects of diets with supplemental DL-methionine (DLM) or DL-2-hydroxy-4-methylthiobutyrate (HMTBA) on the milk free amino acid concentrations $(\mu \mathrm{mol} / \mathrm{l})$ of sows on postpartum day 21

(Mean values with their pooled standard errors)

\begin{tabular}{lcccc}
\hline Amino acids & CON & DLM & HMTBA & Pooled SEM \\
\hline Met & 14 & 22 & 22 & 6 \\
Lys & 65 & 76 & 70 & 19 \\
Thr & 29 & 20 & 29 & 8 \\
Leu & $24^{\mathrm{b}}$ & $46^{\mathrm{a}}$ & $29^{\mathrm{b}}$ & 8 \\
Ile & 8 & 17 & 16 & 6 \\
Phe & $13^{\mathrm{b}}$ & $31^{\mathrm{a}}$ & $15^{\mathrm{b}}$ & 7 \\
Val & $26^{\mathrm{b}}$ & $37^{\mathrm{a}}$ & $35^{\mathrm{a}, \mathrm{b} *}$ & 5 \\
His & $30^{\mathrm{a}, \mathrm{b}}$ & $24^{\mathrm{b}}$ & $53^{\mathrm{a} *}$ & 13 \\
Pro & 223 & 226 & 188 & 34 \\
Arg & 51 & 67 & 63 & 13 \\
Cys & 18 & 20 & 26 & 8 \\
Ala & $131^{\mathrm{b}}$ & $168^{\mathrm{a}, \mathrm{b}}$ & $234^{\mathrm{a}}$ & 46 \\
Ser & 38 & 46 & 58 & 12 \\
Glu & 262 & 303 & 252 & 71 \\
Gly & 220 & 226 & 192 & 46 \\
Tyr & $26^{\mathrm{b}}$ & $50^{\mathrm{a}}$ & $30^{\mathrm{b}}$ & 10 \\
Orn & 19 & 17 & 28 & 7 \\
Tau & $1260^{\mathrm{b}}$ & $1579^{\mathrm{a}, \mathrm{b} *}$ & $1660^{\mathrm{a}}$ & 198 \\
\hline
\end{tabular}

CON, control.

${ }^{a, b}$ Mean values within a row with unlike superscript letters were significantly different $(P<0.05)$

* Mean value tended to be different from that of the CON group $(P<0 \cdot 10)$.

postnatal day 21 are summarised in Table 9. Plasma free cysteine concentrations were higher $(P<0.05)$ in the HMTBA treatment group than in the DLM and CON treatment groups. Plasma free citrulline concentrations were higher $(P<0.05)$ in the CON treatment group than in the DLM and HMTBA treatment groups. Plasma free glutamate concentrations showed a tendency $(P<0 \cdot 10)$ to be affected by the dietary treatments.

\section{Intestinal morphology and goblet cell numbers}

The effects of weaning time, dietary treatment, weaning time $\times$ dietary treatment interaction, weaning time $\times$ intestinal site interaction and dietary treatment $\times$ intestinal site interaction on intestinal morphology and goblet cell numbers of piglets are shown in Fig. 3. Representative staining of goblet cells in each group of piglets is shown in Fig. 4. Overall, piglets weaned at $21 \mathrm{~d}$ of age had higher $(P<0 \cdot 01)$ villus height, lower $(P<0 \cdot 01)$ crypt depth and thus higher $(P<0 \cdot 01)$ percentage of villus height to crypt depth (PVHCD) than those weaned at $28 \mathrm{~d}$ of age (Fig. 3(A)). Dietary treatment also had a significant $(P<0.01)$ effect on intestinal morphology and goblet cell numbers (Fig. 3(B)). Among the three dietary treatment groups, the HMTBA diet-fed piglets had higher $(P<0.05)$ villus height and PVHCD than the CON diet- and DLM diet-fed piglets, whereas the CON diet-fed piglets had lower $(P<0.05)$ goblet cell numbers than the DLM diet- and HMTBA diet-fed piglets (Fig. 3(B)). In Fig. 3(C), the effect of weaning time $\times$ dietary treatment interaction on villus height $(P<0.05)$ and goblet cell numbers $(P<0 \cdot 01)$ is shown. The villus height and goblet cell numbers of piglets weaned at $21 \mathrm{~d}$ of age were higher $(P<0.05)$ in the HMTBA treatment group than in the CON and DLM treatment groups, and the goblet cell numbers of piglets weaned at $28 \mathrm{~d}$ of age were higher
$(P<0.05)$ in the DLM treatment group than in the CON and HMTBA treatment groups. In Fig. 3(D), the effect of weaning time $\times$ intestinal site interaction on villus height $(P<0.01)$, PVHCD $(P<0.05)$ and goblet cell numbers $(P<0.01)$ is shown. Compared with piglets weaned at $21 \mathrm{~d}$ of age, those weaned at $28 \mathrm{~d}$ of age had lower $(P<0.05)$ villus height and PVHCD in both the jejunum and ileum, lower $(P<0.05)$ goblet cell numbers in the duodenum, and higher $(P<0.05)$ goblet cell numbers in the jejunum. In Fig. 3(E), the effect of dietary treatment $x$ intestinal site interaction on goblet cell numbers is shown $(P<0 \cdot 01)$. Both the HMTBA and DLM treatment groups had higher $(P<0.05)$ goblet cell numbers in the duodenum and ileum than the CON treatment group. In contrast, villus height, crypt depth and PVHCD were not affected $(P>0 \cdot 10)$ by dietary treatment $\times$ intestinal site interaction.

\section{Antioxidant capacity}

In Fig. 5(A), the effect $(P<0 \cdot 01)$ of dietary treatment on jejunal GSH content, GSSG content and POGRG (percentage of GSSG to GSH) is shown. Compared with the CON treatment group, both the DLM and HMTBA treatment groups had higher $(P<0.05)$ intestinal GSH and GSSG contents. Moreover, among the three dietary treatment groups, the HMTBA and DLM treatment groups had the highest GSH and GSSG contents, respectively. As a result, POGRG was lower $(P<0.05)$ in the HMTBA treatment group than in the CON and DLM treatment groups. In Fig. 5(B), the effect of PW day $(P<0 \cdot 01)$ on plasma GPx activity and jejunal GSH content, GSSG content and POGRG is shown. Plasma GPx activity was higher $(P<0.05)$ on PW day 7 than on PW days 0 and 14. Decreased $(P<0.05)$ intestinal GSH content and increased $(P<0 \cdot 05)$ GSSG content were observed on PW day 7 than on

Table 9. Effects of sow diets with supplemental DL-methionine (DLM) or DL-2-hydroxy-4-methylthiobutyrate (HMTBA) on the plasma free amino acid concentrations $(\mu \mathrm{mol} / \mathrm{l})$ of suckling piglets on postnatal day 21

(Mean values with their pooled standard errors)

\begin{tabular}{lrrrr}
\hline Amino acids & CON & DLM & HMTBA & Pooled SEM \\
\hline Met & 37 & 39 & 49 & 14 \\
Lys & 155 & 159 & 174 & 25 \\
Leu & 140 & 162 & 166 & 28 \\
Ile & 88 & 104 & 101 & 19 \\
Phe & 79 & 78 & 73 & 11 \\
Val & 199 & 227 & 201 & 42 \\
His & 44 & 47 & 54 & 11 \\
Pro & 405 & 374 & 397 & 71 \\
Arg & 86 & 73 & 74 & 18 \\
Cys & $6 \cdot 1^{\mathrm{b}}$ & $4.9^{\mathrm{b}}$ & $11 \cdot 1^{\mathrm{a}}$ & 2 \\
Ala & 585 & 719 & 694 & 109 \\
Ser & 204 & 181 & 191 & 28 \\
Glu & 77 & 113 & 72 & 24 \\
Gly & 685 & 733 & 672 & 142 \\
Tyr & 135 & 133 & 147 & 19 \\
Cit & $91^{\mathrm{a}}$ & $58^{\mathrm{b}}$ & $62^{\mathrm{b}}$ & 17 \\
Orn & 41 & 43 & 46 & 9 \\
Tau & 79 & 78 & 106 & 23 \\
\hline
\end{tabular}

CON, control.

${ }^{\mathrm{a}, \mathrm{b}}$ Mean values within a row with unlike superscript letters were significantly different $(P<0.05)$. 

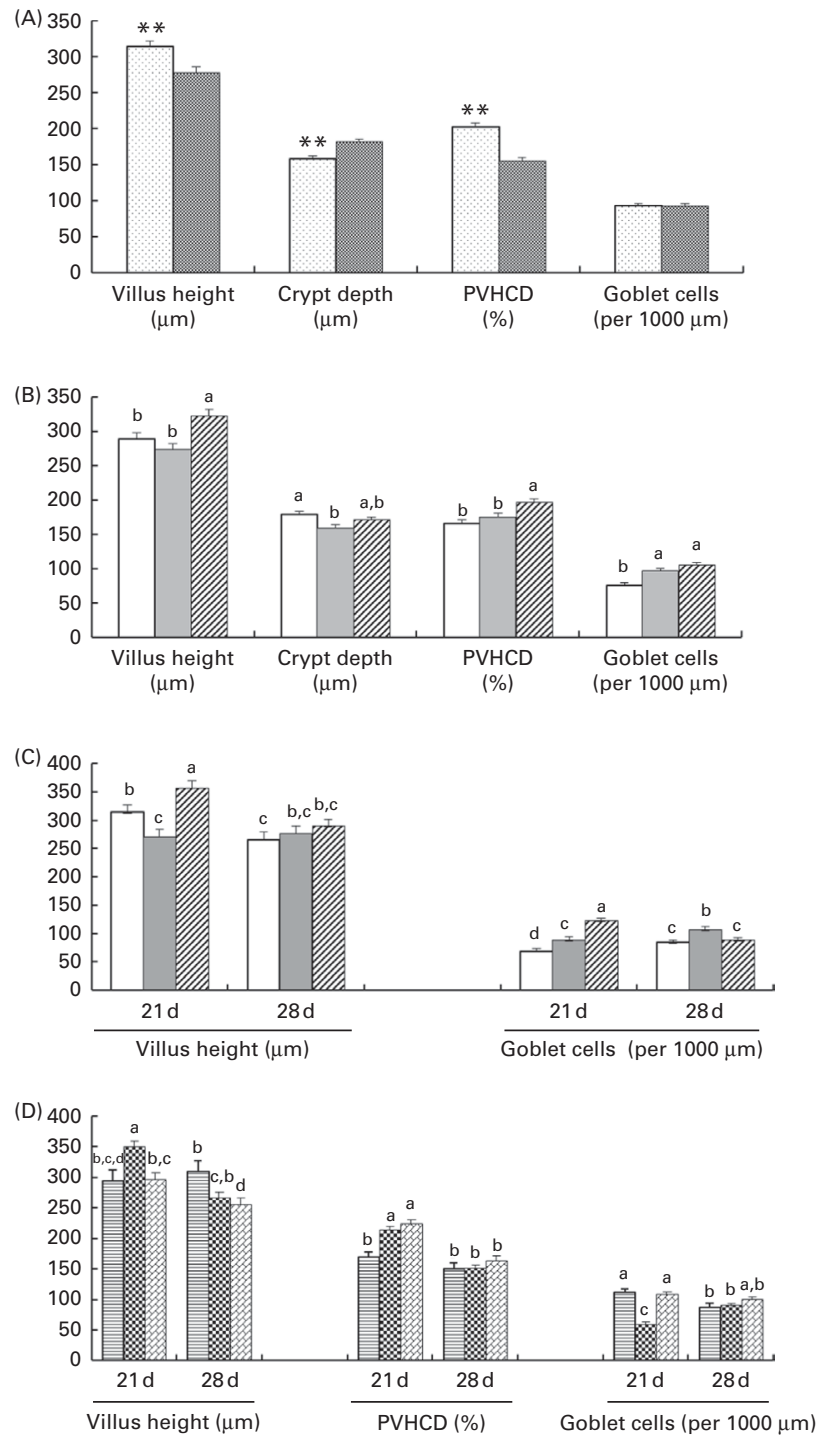

(E)

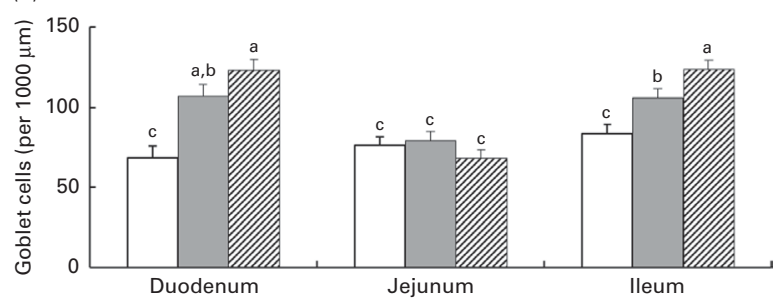

Fig. 3. Effects of $(A)$ weaning time (B, $21 \mathrm{~d}$; $\mathbb{*}, 28 \mathrm{~d}$ ), (B) dietary treatment, (C) weaning time $\times$ dietary treatment interaction, (D) weaning time $\times$ intestinal site interaction and $(E)$ dietary treatment $x$ intestinal site interaction ( $\square$, control; $\square$, DL-methionine; $\square$, DL-2-hydroxy-4-methylthiobutyrate; 目, duodenum; 图, jejunum; 图, ileum) on the intestinal morphology and goblet cell numbers of piglets on postnatal day 35 . Values are means, with their standard errors represented by vertical bars. ${ }^{a, b, c, d}$ Mean values with unlike letters were significantly different $(P<0 \cdot 05)$. ${ }^{\star \star}$ Mean values were significantly different between the dietary treatment groups $(P<0.01)$. PVHCD, percentage of villus height to crypt depth.

PW day 0 . Increased $(P<0.05)$ GSH content and decreased $(P<0.05)$ GSSG content were observed on PW day 14 than on PW day 7 , but neither GSH content nor GSSG content was restored to the level observed on PW day 0.
Accordingly, POGRG was higher $(P<0.05)$ on PW day 14 than on PW day 0 , but was lower $(P<0.05)$ than that observed on PW day 7. Plasma GPx activity (Fig. 5(C)), intestinal GSH content (Fig. 5(D)), GSSG content (Fig. 5(E)) and POGRG (Fig. 5(F)) were affected $(P<0 \cdot 01)$ by dietary treatment $\times$ PW day interaction. As shown in Fig. 5(C), both the CON and DLM

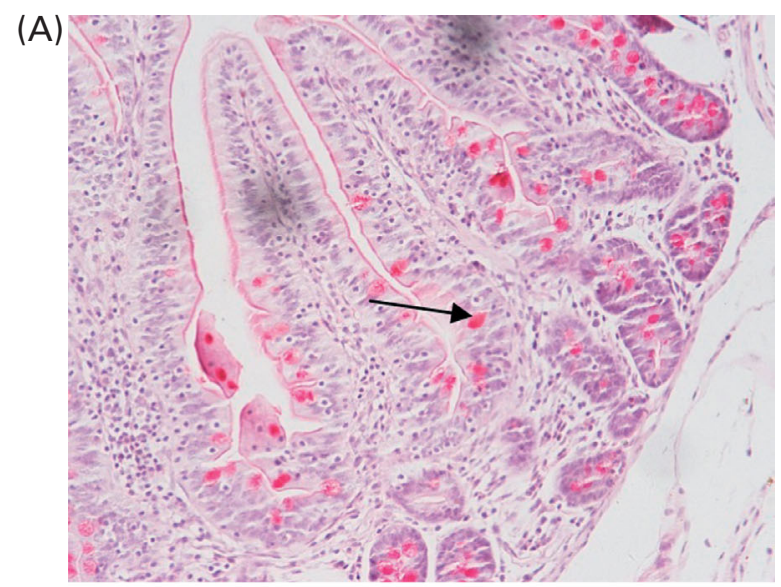

(B)
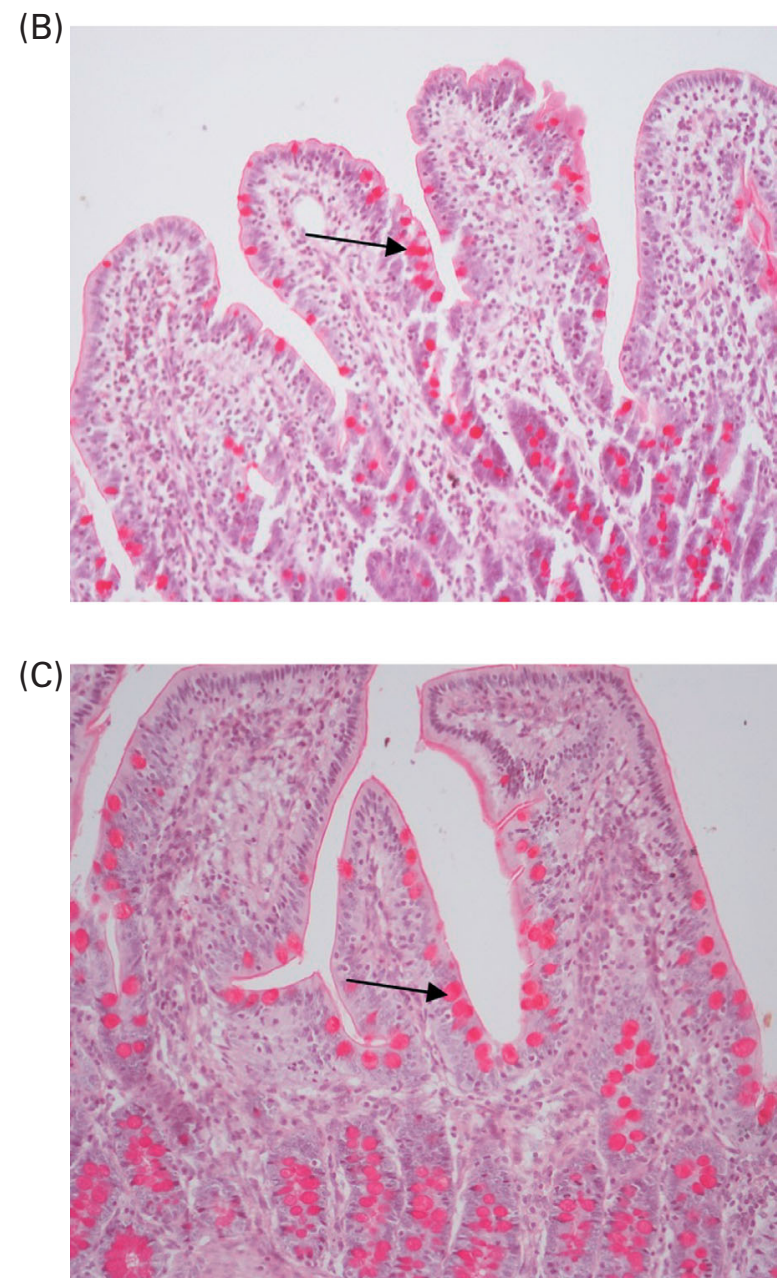

Fig. 4. Representative staining (200x) of ileal goblet cells in the (A) control, (B) DL-methionine and (C) DL-2-hydroxy-4-methylthiobutyrate diet-fed groups of pigs. 
(A)

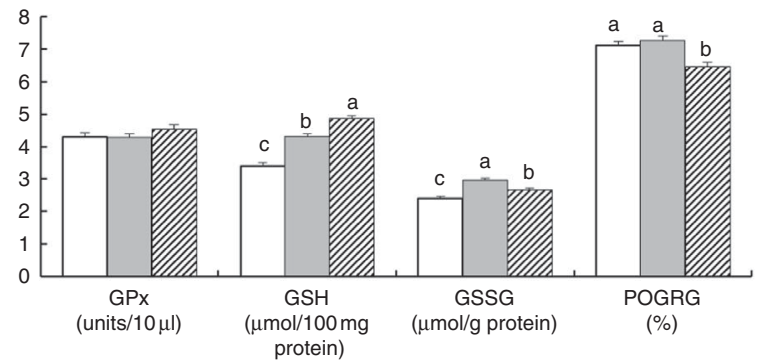

(B)
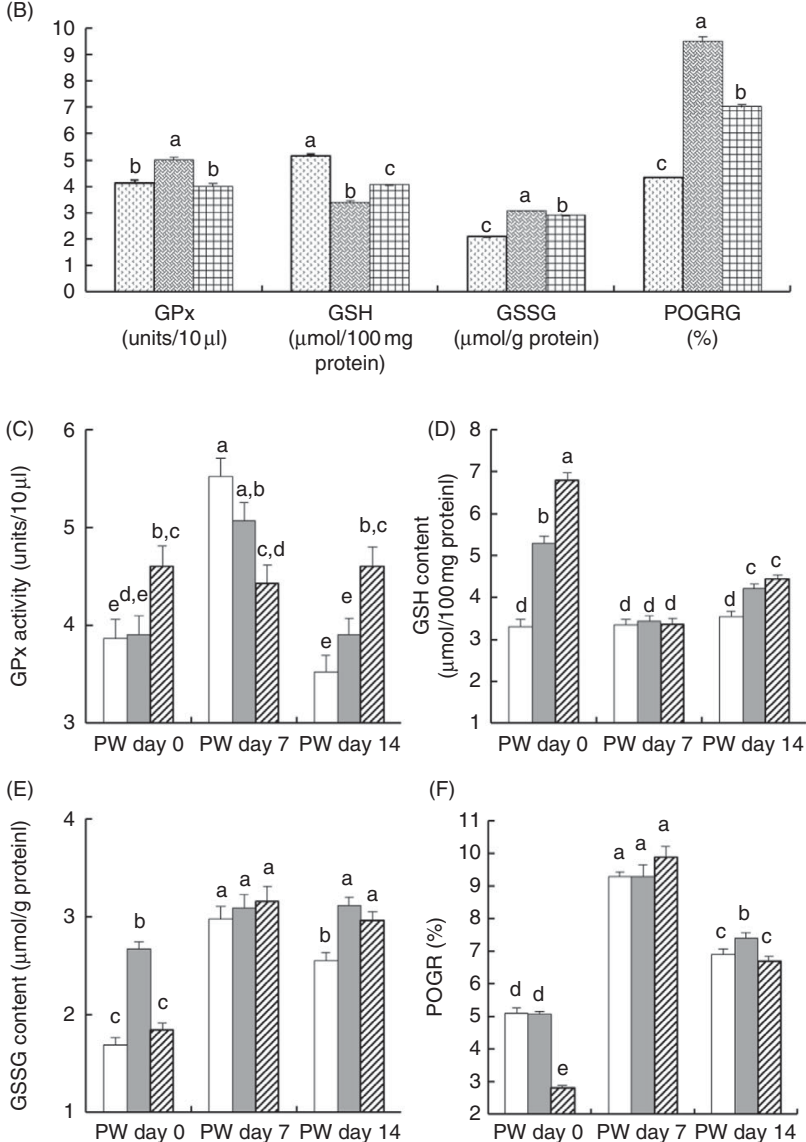

(F)

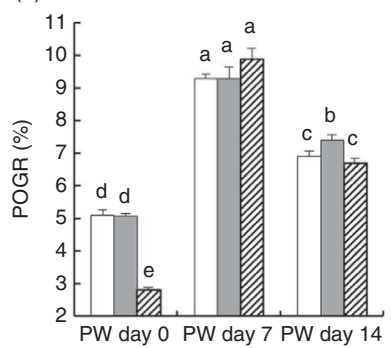

Fig. 5. Effects of $(A)$ dietary treatment, $(B)$ post-weaning $(P W)$ day and $(C-F)$ dietary treatment $\times \mathrm{PW}$ day interaction ( $\square$, control; $\square$, DL-methionine; $\mathbb{Z}$, DL-2-hydroxy-4-methylthiobutyrate; 圈, PW day 0; 图, PW day 7; 柬, PW day 14) on the antioxidant capacity of piglets weaned at $21 \mathrm{~d}$ of age. Values are means, with their standard errors represented by vertical bars. ${ }^{a, b, c, d, e}$ Mean values with unlike letters were significantly different $(P<0.05)$. GPx, glutathione peroxidase; GSH, reduced glutathione; GSSG, oxidised glutathione; POGRG, percentage of oxidised glutathione to reduced glutathione.

treatment groups had higher $(P<0.05)$ GPx activity on PW day 7 than on PW days 0 and 14. In contrast, there was little variation in plasma GPx activity in the HMTBA treatment group from PW day 0 to day 14 , and it was higher $(P<0.05)$ than that in the CON and DLM treatment groups on PW days 0 and 14. On PW day 0, intestinal GSH content was highest in the HMTBA treatment group, followed by that in the DLM treatment group, and lowest in the CON treatment group (Fig. 5(D)), intestinal GSSG content was higher $(P<0.05)$ in the DLM treatment group than in the CON and HMTBA treatment groups (Fig. 5(E)), and POGRG was lower $(P<0.05)$ in the HMTBA treatment group than in the CON and DLM treatment groups (Fig. 3(F)). The three dietary treatment groups had increased $(P<0.05)$ GSSG content (Fig. 5(E)) and POGRG (Fig. 5(F)) on PW day 7 than on PW day 0, whereas GSH content (Fig. 5(D)) in the DLM and HMTBA treatment groups was lower $(P<0.05)$ on PW day 7 than on PW day 0 . On PW day 14, both intestinal GSH content (Fig. 5(D)) and GSSG content (Fig. 5(E)) were higher $(P<0.05)$ in the DLM and HMTBA treatment groups than in the CON treatment group, but POGRG was lower $(P<0.05)$ in the HMTBA treatment group than in the DLM treatment group (Fig. 5(F)).

\section{Gene expression in the jejunum of piglets}

In Fig. 6, the effects of weaning time, PW day, dietary treatment and weaning time $\times$ PW day interaction on the relative mRNA abundances of genes related to nutrient transport in the jejunum of piglets are shown. Overall, piglets weaned at $21 \mathrm{~d}$ of age had higher mRNA abundances of apo A-IV precursor $(P<0.01)$ and $\mathrm{Na}$ - and $\mathrm{Cl}$-dependent creatine transporter I $(P<0 \cdot 10)$ than those weaned at $28 \mathrm{~d}$ of age (Fig. 6(A)). The mRNA abundances of apo A-IV precursor $(P<0 \cdot 05)$, Na- and Cl-dependent creatine transporter I $(P<0 \cdot 01)$ and FZHUI fatty acid-binding protein $(P<0 \cdot 01)$ were lower on PW day 7 than on PW day 0 (Fig. 6(B)). Dietary treatment also had a significant $(P<0.05)$ effect on the mRNA abundance of FZHUI fatty acid-binding protein, which was lower $(P<0.05)$ in the HMTBA treatment group than in the CON and DLM treatment groups (Fig. 6(C)). In Fig. 6(D), the effect $(P<0.05)$ of weaning time $\times \mathrm{PW}$ day interaction on the mRNA abundance of apo A-IV precursor is shown; the mRNA abundance of apo A-IV precursor was lower on PW day 7 than on PW day 0 in piglets weaned at $21 \mathrm{~d}$, but no difference was observed between PW days in piglets weaned at $28 \mathrm{~d}$ of age.

\section{Discussion}

The primary aim of the present study was to determine whether early weaning-induced growth retardation could be attenuated by increased consumption of methionine as DLM or its hydroxyl analogue (HMTBA) in both lactating sows and weaned piglets. Given that the lactation performance of sows is, to a great extent, affected by feed intake ${ }^{(34)}$, which is correlated with parity, genotype and body status ${ }^{(35)}$, primiparous sows having similar genetic background, body weight and backfat thickness were used in the present experiment. It has also been shown that maternal tissue mobilisation and nutrient requirements during lactation period are affected by litter size ${ }^{(36)}$. Therefore, all litters were standardised as described previously ${ }^{(37)}$ to have the same number of piglets. Based on the above control, we found no statistical difference in feed intake among the dietary treatment groups during the experimental phases. This may allow us to discuss the difference in lactation performance in association with dietary treatments, specifically methionine levels and sources.

In the present study, the body weight of piglets averaged over postnatal days was found to be higher in the HMTBA 

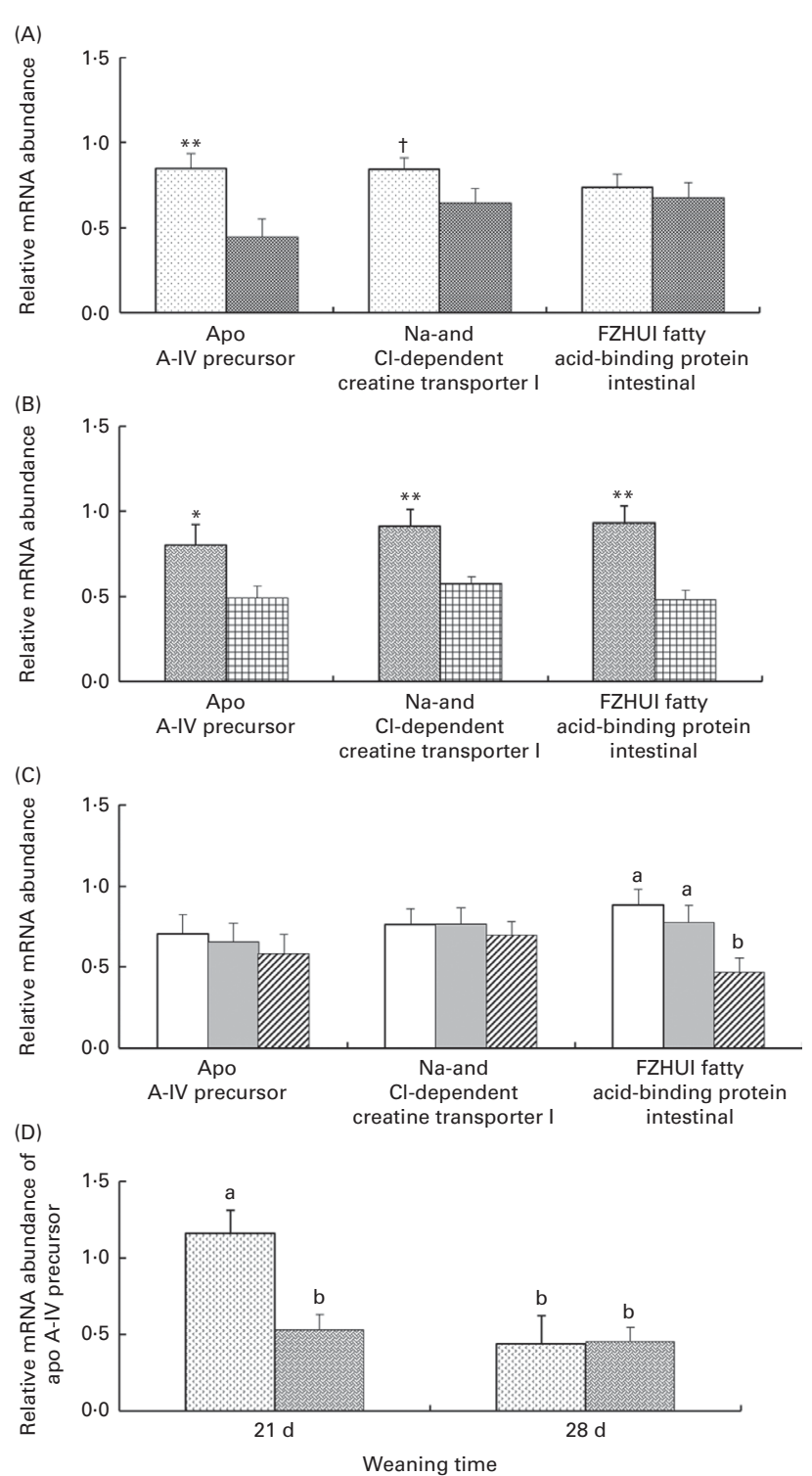

Fig. 6. Effects of (A) weaning time (장, $21 \mathrm{~d}$;, $28 \mathrm{~d}$ ), (B) post-weaning (PW) day, (C) dietary treatment ( $\square$, control; $\square$, DL-methionine; $\square$, DL-2-hydroxy-4methylthiobutyrate and (D) weaning time $\times P W$ day interaction (回, PW day 0 ; 梱, PW day 7) on the relative mRNA abundances of genes related to nutrient transport in the jejunum of piglets. Values are means, with their standard errors represented by vertical bars. ${ }^{\mathrm{a}, \mathrm{b}}$ Mean values with unlike letters were significantly different $(P<0.05)$. Mean values were significantly different: ${ }^{*} P<0.05,{ }^{* *} P<0.01$. † Mean values tended to be different between the dietary treatment groups $(P<0 \cdot 10)$.

treatment group than in the CON and DLM treatment groups. To our knowledge, weaning is always associated with a reduction in food intake in young mammals including piglets ${ }^{(8,38)}$. The higher feed intake averaged over PW days may account for the faster growth of the HMTBA diet-fed piglets. Compared with age-matched piglets weaned at $28 \mathrm{~d}$ of age, piglets weaned at $21 \mathrm{~d}$ of age grew slower during postnatal days $21-28$, but grew faster during postnatal days $28-35$, which is in good agreement with the results of previous studies $^{(3,39)}$. These observations indicate the negative effect of weaning on piglet growth, especially during the first few
PW days. In addition, on postnatal day 35, piglets weaned at $28 \mathrm{~d}$ of age tended to weigh more than those weaned at $21 \mathrm{~d}$ of age in the DLM treatment group; however, the body weight of piglets on postnatal day 35 in the HMTBA treatment group was not different between the weaning ages. These results indicate that increased consumption of methionine as HMTBA might alleviate stresses associated with early weaning.

The secondary aim of the present study was to investigate the mechanisms underlying the responses of lactating sows and their offspring to increased consumption of methionine sources. An important finding was that plasma and milk AA profiles were responsive to the increased consumption of methionine as DLM or HMTBA. The DLM diet-fed sows had lower plasma lysine and isoleucine concentrations than the CON diet- and HMTBA diet-fed sows. The decreased lysine concentrations may be associated with the fact that lysine and methionine share the $\mathrm{B}^{0,+}$ and $\mathrm{b}^{0,+}$ transport systems in mammalian intestine ${ }^{(40)}$. In support of this view, Hagihira et $a l .^{(41)}$ first demonstrated mutual inhibition between arginine, cystine, lysine and ornithine and observed some inhibition by methionine in the intestinal epithelium. A down-regulation effect of L-methionine on these transporters has also been reported for broiler chickens as a means to lower the risk of methionine intoxication ${ }^{(42)}$. Lysine is often considered to be the first limiting AA for lactating sows sustaining milk synthesis, particularly when diets are based on maize and soyabean meal as the main protein sources ${ }^{(6)}$. Recent studies have indicated that isoleucine plays an important role in the activation of mammalian target of rapamycin signalling, which is a control point in milk protein synthesis $^{(43)}$. It appears that the lower concentrations of isoleucine and lysine in the plasma of the DLM diet-fed sows may limit these two AA available for delivery to the mammary gland and thus limit milk synthesis. This may be further supported by the observation that the higher free leucine, valine, phenylalanine and tyrosine concentrations in the milk of the DLM diet-fed sows did not cause a difference in the body weight of 21-d-old piglets among the dietary treatment groups. There is evidence that intestinal mucosal catabolism of branched-chain AA may provide nitrogen for the synthesis of both alanine and glutamate ${ }^{(44)}$. It has also been observed that the extensive catabolism of branchedchain AA in extra-intestinal tissues stimulates the synthesis of glutamate and glutamine ${ }^{(45,46)}$. It appears that the higher concentrations of leucine and valine in the milk of the DLM diet-fed sows might explain the potential change in piglet plasma glutamate concentrations, which exhibited a tendency to be affected by the dietary treatments.

The concentrations of non-essential AA including taurine, citrulline and alanine in plasma and milk were also affected by increased consumption of methionine as DLM or HMTBA. Given that taurine is an end product of methionine metabolism, the higher taurine concentrations in the plasma and milk of the DLM diet- and HMTBA diet-fed sows than in those of the CON diet-fed sows might be due to the increased availability of methionine, which showed a tendency to be affected by the dietary treatments. Increased alanine concentrations and 
decreased citrulline concentrations in plasma were also observed following DLM and HMTBA supplementation compared with those in the CON diet-fed sows. In a previous study, the uptake of glutamine in vivo and the release of citrulline by the small intestine have been observed in pigs $^{(47)}$. In this regard, the higher concentrations of citrulline in plasma indicate that more amounts of glutamine were catabolised in the intestine of the CON diet-fed sows. Branched-chain AA catabolism has been shown to be an important rate-limiting event in alanine production in vivo ${ }^{(48)}$. The decreased plasma isolecuine concentrations appear to be suggestive of more extensive catabolism, which may account for the increased alanine production in the DLM diet-fed sows.

The intestine is considered to be most susceptible to weaning stresses $^{(8,38)}$. Moreover, gastrointestinal dysfunction has been shown to be physiologically strongly associated with early weaning-induced oxidative stress $^{(3)}$. Thus, the antioxidant capacity was evaluated to determine the mechanisms that account for the differences among piglets consuming different levels and sources of methionine. Weaning was found to lead to elevated plasma GPx activity and intestinal GSSG:GSH ratio in piglets in the CON and DLM treatment groups, which is in good agreement with the results of recent studies ${ }^{(49)}$. It has been established that GPx and glutathione play an important role in the maintenance of redox balance of cells through the elimination of reactive oxygen species such as $\mathrm{H}_{2} \mathrm{O}_{2}^{(50)}$, which can be converted into oxygen through coupled reactions with the conversion of GSH into GSSG, catalysed by GPx. The GSSG:GSH ratio has been shown to be a good measure of oxidative stress of an organism ${ }^{(51)}$. The increased GPx activity accompanied by an increased GSSG:GSH ratio, as has been observed in the present study and previous studies ${ }^{(49)}$, indicates that the variation in GPx activity is an adaptive response to oxidative stress associated with early weaning. Interestingly, increased consumption of methionine as HMTBA in lactating sows and weaned piglets resulted in relatively constant plasma GPx activity in piglets from PW day 0 to day 14 . One possible explanation is that the increased plasma cysteine concentrations may enhance the capacity of reactive oxygen species elimination. In support of this view, cysteine is particularly sensitive to reactive oxygen species and thus is a quantitatively important reactive oxygen species scavenger ${ }^{(52)}$. Given that the synthesis of both the major cellular reductant, glutathione $^{(9)}$, and the major extracellular reductant, cysteine $^{(10)}$, depends on the AA cysteine or its precursor, methionine ${ }^{(11)}$, the higher intestinal GSH content and plasma cysteine concentrations at weaning and the lower GSSG:GSH ratio as observed at weaning and PW day 14 may reflect the high efficiency of methionine source as HMTBA than as DLM to enhance the antioxidant capacity of piglets. In addition, consistent with previous studies ${ }^{(3)}$, it was found that the expression of intestinal transport genes including apo A-IV precursor, FZHUI fatty acid-binding protein and $\mathrm{Na}$ - and Cl-dependent creatine transporter $\mathrm{I}$ in the jejunum of piglets was lower on PW day 7 than on PW day 0 , indicating the significant role of weaning in the reduction of the expression of these transport genes. Interestingly, the expression of FZHUI fatty acid-binding protein was also affected by the dietary treatments with a down-regulated expression being observed in the HMTBA treatment group, the underlying mechanism of which remains to be elucidated. Compared with the CON treatment group, higher villus height and villus height:crypt depth ratio and higher number of goblet cells were also observed in the intestine of piglets in the HMTBA treatment group, which provides further evidence for the alleviated weaning stresses following HMTBA consumption.

In summary, increased consumption of methionine as HMTBA was found to alleviate early weaning-induced growth retardation in piglets, which is physiologically associated with elevated amounts of SAA available for delivery to extra-intestinal tissues without compromising lysine and isoleucine availability, and promote growth performance and antioxidant capacity of the intestine. This novel finding may have important implications for the nutritional management of lactating sows and weaning piglets.

\section{Acknowledgements}

The authors thank Professor Mei Yu at Huazhong Agricultural University for her valuable assistance in statistical analysis.

The present study was supported by the Rhodimet Research Grant from Adisseo France S.A.S., Briand, Antony Cedex, France, the National Natural Science Foundation of China (30901042), and the Sichuan Province Science Foundation for Fostering Youths Talents (2011JQ0015).

The authors' contributions are as follows: Z. F. designed the study; H. L., H. W., X. Z., C. W., X. W., L. T., L. C., Y. L., S. X. and G. T. carried out the study; Z. F., Y. M., D. W. and H. L. analysed the data and wrote the article.

The authors declare potential conflict of interest, given that Y. M. is an employee of Adisseo, one of financial supporters of the present study.

\section{References}

1. Shankar B, Madhusudhan H \& Harish DB (2009) Pre-weaning mortality in pig - causes and management. Vet World 2, 236-239.

2. Smith F, Clark JE, Overman BL, et al. (2010) Early weaning stress impairs development of mucosal barrier function in the porcine intestine. Am J Physiol Gastrointest Liver Physiol 298, G352-G363.

3. Wang J, Chen L, Li P, et al. (2008) Gene expression is altered in piglet small intestine by weaning and dietary glutamine supplementation. J Nutr 138, 1025-1032.

4. Moeser AJ, Ryan KA, Nighot PK, et al. (2007) Gastrointestinal dysfunction induced by early weaning is attenuated by delayed weaning and mast cell blockade in pigs. Am J Physiol Gastrointest Liver Physiol 293, G413-G421.

5. Guan X, Bequette BJ, Ku PK, et al. (2004) The amino acid need for milk synthesis is defined by the maximal uptake of plasma amino acids by porcine mammary glands. J Nutr 134, 2182-2190.

6. NRC (1998) Nutrient Requirements of Swine, 10th ed. Washington, DC: National Academic Press.

7. Dourmad J-Y, Etienne M, Valancogne A, et al. (2008) InraPorc: a model and decision support tool for the nutrition of sows. Anim Feed Sci Technol 143, 372-386. 
8. Gu X, Li D \& She R (2002) Effect of weaning on small intestinal structure and function in the piglet. Arch Tierernahr $\mathbf{5 6}$, $275-286$

9. Wu G, Fang YZ, Yang S, et al. (2004) Glutathione metabolism and its implications for health. J Nutr 134, 489-492.

10. Iyer SS, Ramirez AM, Ritzenthaler JD, et al. (2009) Oxidation of extracellular cysteine/cystine redox state in bleomycininduced lung fibrosis. Am J Physiol Lung Cell Mol Physiol 296, L37-L45.

11. Nkabyo YS, Gu LH, Jones DP, et al. (2006) Thiol/disulfide redox status is oxidized in plasma and small intestinal and colonic mucosa of rats with inadequate sulfur amino acid intake. J Nutr 136, 1242-1248.

12. Bauchart-Thevret C, Stoll B, Chang X, et al. (2008) Sulfur amino acids are necessary for normal intestinal mucosal growth in neonatal piglets. FASEB J 22, 896.1.

13. Bauchart-Thevret C, Stoll B, Chacko S, et al. (2009) Sulfur amino acid deficiency upregulates intestinal methionine cycle activity and suppresses epithelial growth in neonatal pigs. Am J Physiol Endocrinol Metab 296, E1239-E1250.

14. Fang Z, Yao K, Zhang X, et al. (2010) Nutrition and health relevant regulation of intestinal sulfur amino acid metabolism. Amino Acids 39, 633-640.

15. Fang Z, Luo J, Qi Z, et al. (2009) Effects of 2-hydroxy4-methylthiobutyrate on portal plasma flow and net portal appearance of amino acids in piglets. Amino Acids 36, 501-509.

16. Fang Z, Luo H, Wei $\mathrm{H}$, et al. (2010) Methionine metabolism in piglets fed DL-methionine or its hydroxy analogue was affected by distribution of enzymes oxidizing these sources to keto-methionine. J Agric Food Chem 58, 2008-2014.

17. Fang Z, Huang F, Luo J, et al. (2010) Effects of DL-2-hydroxy4-methylthiobutyrate on the first-pass intestinal metabolism of dietary methionine and its extra-intestinal availability. Br J Nutr 103, 643-651.

18. Daza A, Riopérez J, Centeno C, et al. (2004) Short Communication. Changes in the composition of sows' milk between days 5 to 26 of lactation. Span J Agric Res 2, 333-336.

19. Yin FG, Liu YL, Yin YL, et al. (2009) Dietary supplementation with Astragalus polysaccharide enhances ileal digestibilities and serum concentrations of amino acids in early weaned piglets. Amino Acids 37, 263-270.

20. Deng D, Yao K, Chu W, et al. (2009) Impaired translation initiation activation and reduced protein synthesis in weaned piglets fed a low-protein diet. J Nutr Biochem 20, $544-552$

21. Wu G, Meier SA \& Knabe DA (1996) Dietary glutamine supplementation prevents jejunal atrophy in weaned pigs. J Nutr 126, 2578-2584.

22. Wu X, Ruan Z, Gao Y, et al. (2010) Dietary supplementation with L-arginine or $\mathrm{N}$-carbamylglutamate enhances intestinal growth and heat shock protein-70 expression in weanling pigs fed a corn- and soybean meal-based diet. Amino Acids 39, 831-839.

23. Kong XF, Yin YL, He QH, et al. (2008) Dietary supplementation with Chinese herbal powder enhances ileal digestibilities and serum concentrations of amino acids in young pigs. Amino Acids 37, 573-582.

24. Yin FG, Yin YL, Li TJ, et al. (2011) Developmental changes of serum amino acids in suckling piglets. J Food Agric Environ 9, 322-327.

25. Berkeveld M, Langendijk P, Soede NM, et al. (2009) Improving adaptation to weaning: effect of intermittent suckling regimens on piglet feed intake, growth, and gut characteristics. J Anim Sci 87, 3156-3166.
26. Piel C, Montagne L, Seve B, et al. (2005) Increasing digesta viscosity using carboxymethylcellulose in weaned piglets stimulates ileal goblet cell numbers and maturation. $J$ Nutr 135, 86-91.

27. Lora J, Alonso FJ, Segura JA, et al. (2004) Antisense glutaminase inhibition decreases glutathione antioxidant capacity and increases apoptosis in Ehrlich ascitic tumour cells. Eur J Biochem 271, 4298-4306.

28. Bradford MM (1976) A rapid and sensitive method for the quantitation of microgram quantities of protein utilizing the principle of protein-dye binding. Anal Biochem 72, $248-254$.

29. Zhang X-D, Zhu Y-F, Cai L-S, et al. (2008) Effects of fasting on the meat quality and antioxidant defenses of marketsize farmed large yellow croaker (Pseudosciaena crocea). Aquaculture 280, 136-139.

30. Chen Y, Chen DW, Tian G, et al. (2012) Dietary arginine supplementation alleviates immune challenge induced by Salmonella enterica serovar Choleraesuis bacterin potentially through the Toll-like receptor 4-myeloid differentiation factor 88 signalling pathway in weaned piglets. Br J Nutr 108, 1069-1076.

31. Livak KJ \& Schmittgen TD (2001) Analysis of relative gene expression data using real-time quantitative PCR and the 2(-Delta Delta $C(T)$ ) method. Methods 25, 402-408.

32. Petersen YM, Burrin DG \& Sangild PT (2001) GLP-2 has differential effects on small intestine growth and function in fetal and neonatal pigs. Am J Physiol Regul Integr Comp Physiol 281, R1986-R1993.

33. Littell RC, Henry PR \& Ammerman CB (1998) Statistical analysis of repeated measures data using SAS procedures. J Anim Sci 76, 1216-1231.

34. Kruse S, Traulsen I \& Krieter J (2011) Analysis of water, feed intake and performance of lactating sows. Livest Sci $\mathbf{1 3 5}$, 177-183.

35. Eissen JJ, Kanis E \& Kemp B (2000) Sow factors affecting voluntary feed intake during lactation. Livest Prod Sci 64 , $147-165$.

36. Kim SW \& Easter RA (2001) Nutrient mobilization from body tissues as influenced by litter size in lactating sows. J Anim Sci 79, 2179-2186.

37. Kusina J, Pettigrew JE, Sower AF, et al. (1999) Effect of protein intake during gestation and lactation on the lactational performance of primiparous sows. J Anim Sci 77, 931-941.

38. Miller BG, James PS, Smith MW, et al. (1986) Effect of weaning on the capacity of pig intestinal villi to digest and absorb nutrients. J Agric Sci 107, 579-589.

39. Colson V, Orgeur P, Foury A, et al. (2006) Consequences of weaning piglets at 21 and 28 days on growth, behaviour and hormonal responses. Appl Anim Behav Sci 98, 70-88.

40. Broer S (2008) Amino acid transport across mammalian intestinal and renal epithelia. Physiol Rev 88, 249-286.

41. Hagihira H, Lin EC, Samiy AH, et al. (1961) Active transport of lysine, ornithine, arginine and cystine by the intestine. Biochem Biophys Res Commun 4, 478-481.

42. Soriano-Garcia JF, Torras-Llort M, Moreto M, et al. (1999) Regulation of L-methionine and L-lysine uptake in chicken jejunal brush-border membrane by dietary methionine. $\mathrm{Am}$ J Physiol 277, R1654-R1661.

43. Appuhamy JA, Knoebel NA, Nayananjalie WA, et al. (2012) Isoleucine and leucine independently regulate mTOR signaling and protein synthesis in MAC-T cells and bovine mammary tissue slices. J Nutr 142, 484-491.

44. Chen L, Li P, Wang J, et al. (2009) Catabolism of nutritionally essential amino acids in developing porcine enterocytes. Amino Acids 37, 143-152. 
45. Wu G, Thompson JR, Sedgwick GW, et al. (1989) Formation of alanine and glutamine in chick (Gallus domesticus) skeletal muscle. Comp Biochem Physiol B 93, 609-613.

46. Li P, Knabe DA, Kim SW, et al. (2009) Lactating porcine mammary tissue catabolizes branched-chain amino acids for glutamine and aspartate synthesis. J Nutr 139, 1502-1509.

47. Wu G, Borbolla AG \& Knabe DA (1994) The uptake of glutamine and release of arginine, citrulline and proline by the small intestine of developing pigs. J Nutr 124, 2437-2444.

48. Haymond MW, Ben-Galim E \& Strobel KE (1978) Glucose and alanine metabolism in children with maple syrup urine disease. J Clin Invest 62, 398-405.
49. Degroote J, Michiels J, Claeys E, et al. (2012) Changes in the pig small intestinal mucosal glutathione kinetics after weaning. J Anim Sci 90, Suppl. 4, 359-361.

50. Trachootham D, Lu W, Ogasawara MA, et al. (2008) Redox regulation of cell survival. Antioxid Redox Signal 10, $1343-1374$.

51. Dröge W (2002) Aging-related changes in the thiol/disulfide redox state: implications for the use of thiol antioxidants. Exp Gerontol 37, 1333-1345.

52. Stadtman ER (1993) Oxidation of free amino acids and amino acid residues in proteins by radiolysis and by metalcatalyzed reactions. Annu Rev Biochem 62, 797-821. 